\title{
Editorial
}

\section{A Radiologia Brasileira nos próximos anos}

A Radiologia como área do conhecimento médico apresentou enorme evolução nos últimos anos. Ao lado da evolução tecnológica dos equipamentos, houve toda uma proliferação de informações nas diversas subespecialidades, que acabaram a segmentar a especialidade em sistemas.

Hoje, é impossível para o radiologista conseguir dominar todos os sistemas e técnicas. Isto levou a uma atividade profissional que passou de trabalho solitário a trabalho em grupo.

Este aspecto, sem dúvida, tornou-se uma nova face da especialidade e um novo desafio a ser vencido.

No âmbito científico, a Radiologia Brasileira também deve adequar-se às mudanças que houve no cenário nacional e internacional.

A Radiologia cresceu qualitativamente e quantitativamente em todo o território nacional. A Radiologia Brasileira deve ser o veículo de difusão desta expansão da especialidade, do ponto de vista científico e de conhecimentos que possam ser úteis para a sua atualização.

Deve-se fazer duas importantes considerações:

A primeira, é o pouco estímulo que a maior parte dos radiologistas envolvidos em atividades clínicas tem para realizar trabalhos para publicação.

A segunda, é que radiologistas envolvidos em escolas médicas de liderança procuram cada vez mais publicar seus trabalhos em revistas de língua inglesa, para ter maior difusão e reconhecimento internacional.

Contudo, quando observamos o crescimento da sessão de "posters" dos nossos Congressos, vemos que há grande possibilidade de incremento do material a ser publicado na Radiologia Brasileira. Cada vez mais esses "posters" apresentam qualidade de contribuição original.

É a esses autores que convidamos para transformar seus "posters" em trabalhos originais para a Radiologia Brasileira, para também podermos difundir, em âmbito nacional, essas importantes contribuições da nossa especialidade.

Poderemos, este ano, ter a Revista divulgada via internet, o que aumentará sua penetração e será outra alternativa de consulta.

A Radiologia Brasileira quer crescer acompanhando a especialidade.

Giovanni Guido Cerri Editor 